\title{
Comunicação
}

\section{O pesquisador-médico: da academia às parcerias}

\author{
C. CSILLAG, N. SCHOR \\ Disciplina de N efrologia da Escola Paulista de Medicina- UNIFESP, São Paulo, SP.
}

\begin{abstract}
RESUMO - Овj etivo. llustrar as mudanças na academia e na indústria que estão levando a uma transformação no perfil do pesquisador-médico.

Método e Resultados. Foram pesquisados dados de literatura, fontes primárias e experiência dos próprios autores.
\end{abstract}

Conclusão. 0 mercado de trabalho passa a pro-

\section{INTRODUÇÃO}

O pesquisador-médico pertence a uma espécie ameaçada de extinção. Ele precisa se adaptar às exi gências do mercado de trabal ho para sobreviver à concorrência dos pesquisadores das áreas bási cas e das subespecialidades clínicas. Se conseguir, será capaz de atender a uma demanda que pesqui sadores sem formação clínica têm mai or dificuldade: dar rumo a projetos de pesquisa em biotecnologia para o combate a doenças. Essa demanda torna-se real quando o setor privado, atrelado às regras do mercado, aproxima-se cada vez mais da área de saúde, tanto em assistência quanto em pesquisa.

\section{Pouco dinheiro no mercado}

E ste ano, a indústria farmacêutica deve faturar no Brasil cerca de US\$10,6 bilhões, de acordo com a Associação Brasileira das I ndústrias Farmacêuticas (Abifarma) (Csillag, C. pers comm, 1998). Estão previstos até o fim do ano um volume razoável de investimentos em produção e vendas, na ordem de US $\$ 380$ mil hões $^{1}$, mas os investimentos em pesqui sas clínicas ou bási cas não devem passar de US\$ 70 milhões (Csillag, C. pers comm, 1998). Ou seja, $0,7 \%$ do faturamento será destinado à pesqui sas. E sses números indicam que a indústria farmacêutica brasileira proporciona uma quantidade considerável de empregos relacionados à produção e comercial ização de produtos, mas relativamente poucas oportunidades de trabal ho para profissionais ligados à pesquisa.

U ma comparação com os E stados U nidos sugere o que esses números representam em termos de investimento. Lá, o faturamento anual da indústria farmacêutica é cerca de seis vezes maior do curar um pesquisador-médico mais adequado a orientar as pesquisas em função de objetivos centrados nos pacientes e em doenças num relacionamento universidade-indústria.

UNITERMOS: Pesquisador-médico. Indústria farmacêutica. Pesquisa acadêmica. Pesquisa clínica.

que o brasileiro - está previsto para ficar em torno de US\$ 66,5 bilhões em 1998². A Pharmaceutical Research and Manufacturers of America (PhRMA) estima que, neste ano, serão investidos em pesquisa e desenvol vimento cerca de US\$20,6 bil hões $^{3}$. I sso significa que $31 \%$ do faturamento do mercado americano serão investidos em pesquisa e desenvolvimento - 44 vezes mais, proporcionalmente, do que no Brasil.

A discrepância relativa não se limita ao setor privado. Na tabela 1 e na figura 1 apresentamos dados que sugerem que apesar do aumento da relação dos dispêndios em ciência e tecnologia estarem proporcionadamente aumentando, em relação ao PIB do Brasil, de 0,70\% em 1990 para 0,88\% em 1995, esta rel ação está defasada se comparada com os principais países produtores da ciência internacional. $\mathrm{Na}$ tabela 2 estão apresentados esses dados de forma comparativa a outros países. Enquanto o Brasil está nos 0,88 \% do PIB (dados disponíveis de 1995), os Estados Unidos estão com 2,5\%, o J apão com 2,7\%, a Alemanha com $2,5 \%$, a F rança com $2,4 \%$ e o Reino Unido com $2,2 \%$. Esta diferença na primeira análise não é chocante, porém deve-se considerar que o parque científico, bem como sua tradição na área de pesquisa destes países, está muito bem estabel ecida, enquanto que no Brasil uma proporção muito menor de laboratórios e mesmo uma menor proporção de pesquisadores/população é observada. Dessa maneira, se pretendemos dar um salto qualitativo em pesquisa, os investimentos nesta área devem ultrapassar em muito os minguados 0,88\% de 1995.

Quando limitados à área de saúde, o investimento público é ainda mais insignificante. $\mathrm{Na}$ tabela 3 , observa-se a ridícula proporção que o Ministério da Saúde(MS) emprega em desenvolvimento da ciência 


\begin{tabular}{|c|c|c|c|c|c|c|}
\hline \multirow[b]{2}{*}{ PIB/Dispêndios } & \multirow[b]{2}{*}{1990} & \multirow[b]{2}{*}{1991} & \multirow[b]{2}{*}{1992} & \multicolumn{3}{|c|}{ Em US $\$$ bilhões de 95} \\
\hline & & & & 1993 & 1994 & 1995 \\
\hline $\mathrm{PIB}^{(\mathrm{a})}$ & 592,0 & 593,4 & 588,8 & 613,0 & 648,6 & 675,8 \\
\hline Dispêndios em C\&T (b,s) (1) & 417 & 411 & 331 & 470 & 500 & $6,0^{(2)}$ \\
\hline DCT/PIB (\%) ${ }^{(1)}$ & 0,70 & 0,69 & 0,56 & 0,77 & 0,77 & 0,88 \\
\hline
\end{tabular}

Fontes: (a) Fundação Instituto Brasileiro de Geografia e Estatística (IBGE); (b) Associação Nacional de Pesquisa e Desenvolvimento das Empresas Industriais (ANPEI); e (c) MCT/CNP/COOE.

Compilado por. MCT/CNPq/SUP/COOE.

Nota: Valores atualizados pelo deflator implícito do PIB e convertidos pela cotação média do dólar de venda de 1995 fornecida pelo Banco Central do Brasil (US $\$ 1,00=R \$ 0,918$ ).

(1) As taxas DCT/PIB e os dispêndios de C\&T para o período 1990-92 são valores estimados. Estes valores foram estimados assumindo-se que a participação relativa do dispêndio federal mais o estadual com relação ao dispêndio global manteve-se constante.

(2) Valor de 1995 inclui uma estimativa de US\$350.000 de salários pagos à pesquisadores das universidades federais, cujo montante aparentemente não é capturado pela sistemática atual. Anos anteriores não incluem estimativa desses salários.

\begin{tabular}{|c|c|c|c|}
\hline País & P\&D/PIB (\%) & País & P\&D/PIB (\%) \\
\hline Brasil (95) (a) (1) & 0,88 & Japão (93) ${ }^{(c)}$ & 2,7 \\
\hline Argentina (94) ${ }^{(b)}$ & 0,31 & Alemanha (93) (c) & 2,5 \\
\hline México (93) (b) & 0,32 & França (93) (c) & 2,4 \\
\hline Venezula (94) (b) & 0,34 & Reino Unido (93) ${ }^{(c)}$ & 2,2 \\
\hline Equador (93) (b) & 0,16 & Itália (94) (c) & 1,2 \\
\hline Estados Unidos (94) (c) & 2,5 & Canadá (94) (c) & 1,5 \\
\hline \multicolumn{4}{|c|}{$\begin{array}{l}\text { Fontes: (a) MCT/CNPq/SUP/COOE; (b) RICYT, Indicadores de Ciência y Tecnologia } \\
\text { 1990-95, Buenos Aires, RICYT/CYTED, 1996, p. 5; (c) National Science and } \\
\text { Indicators - 1996. Washington, DC: U.S. Government Printing Office, Compilado por: MCT/CNPq/SUP/COOE. } \\
\text { (1) O valor registrado para o Brasil refere-se aos dispêndios de Ciência e Tecnologia em 1995. Os Dispêndios } \\
\text { são compostos de P\&D e Atividades Cientificas e Técnicas Correlatas. Estas últimas são atividades de execução } \\
\text { da P\&D. }\end{array}$} \\
\hline
\end{tabular}

\begin{tabular}{|c|c|c|c|c|c|c|c|c|}
\hline Dispêndios & MCT & $\operatorname{MEC}(\mathrm{C})$ & MAARA & PR & MAER & MS & Outros & Total \\
\hline US\$ milhões & 1054,3 & 879 & 398,8 & 184,4 & 82,9 & 74,0 & 135,5 & 2807,0 \\
\hline Percentual & 37,6 & 31,3 & 14,1 & 6,6 & 3,0 & 2,6 & 4,8 & 100,0 \\
\hline \multicolumn{9}{|c|}{$\begin{array}{l}\text { Fonte: MCT/CNPq/SUP/COOE. } \\
\text { Compilado por: MCT/CNPq/SUP/COOE. } \\
\text { Nota: Valores atualizados pelo deflator implícito do PIB e convertidos pela cotação média de venda de 1995, } \\
\text { Banco Central do Brasil (US } \$ 1,00=R \$ 0,918) \\
\text { (1) Valores sujeitos à revisão. Inclui uma estimativa de US } \$ 350.000 \text { em salários de professores }\end{array}$} \\
\hline $\begin{array}{l}\text { MCT - Ministé } \\
\text { MEC - Ministé } \\
\text { MAARA - Mini }\end{array}$ & $\begin{array}{l}\text { iência e } \\
\text { ducação } \\
\text { a Agricul }\end{array}$ & $\begin{array}{l}\text { nologia } \\
\text { Cultura } \\
\text {, Abaste }\end{array}$ & lento e $R e$ & & $\begin{array}{l}\mathrm{PF} \\
\mathrm{M} / \\
\mathrm{MS}\end{array}$ & $\begin{array}{l}\text { residê } \\
\text { - Mini } \\
\text { Ainisté }\end{array}$ & $\begin{array}{l}\text { cia da Rep } \\
\text { ério da } A e \\
\text { da Saúd }\end{array}$ & $\begin{array}{l}\text { blica } \\
\text { onáutica }\end{array}$ \\
\hline
\end{tabular}




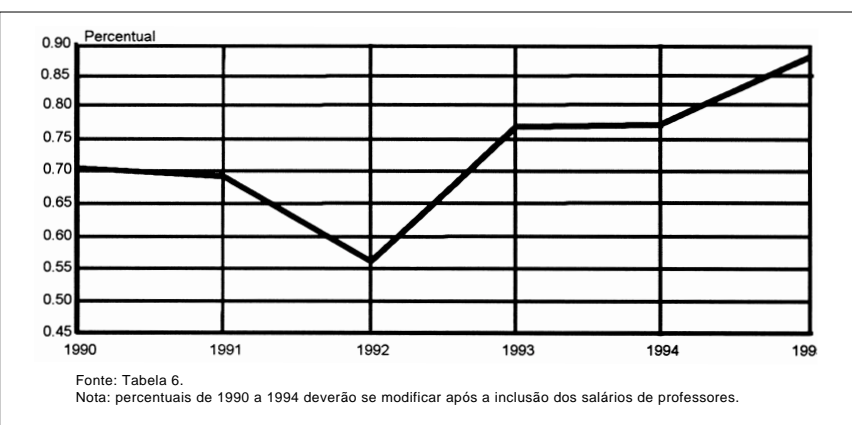

Fig. 1 - Dispêndios em C\&T como Porcentagem do PIB

e tecnologia (C\&T): apenas 2,6\% do total investido pelos principais órgãos federais provém deste ministério.

\section{Quem consegue dinheiro para pesquisa?}

Historicamente, no início dos anos 50, a proposta do National Institutes of Health $(\mathrm{NIH})$, dos Estados U nidos, bem como da Rockeffeler Foundation, contaminou as escolas médicas em todo o mundo, influenciando para que seus melhores alunos se envolvessem em atividades cujo paradigma era a ativi dade mescl ada de médi co-cientista. N esta atividade complexa, os médicos eram estimulados a desenvolver atividades da prática clínica associada à pesqui sa básica, voltadas a atender o cotidiano encontrado na observação da atividade médica ambulatorial e nas enfermarias. O paradigma baseava-se no pressuposto de que só seria possível entender e curar as doenças se a pesquisa básica fosse desenvolvi da tanto em situação normal/fisiológica como na patológica/fisi opatológica. Este estímulo com o epicentro nos EUA produziu um enorme esforço de pós-guerra, fazendo com que a ciência médica fosse impulsionada, com substancial sucesso. A fórmula de pesquisador-médico em um período do trabalho, intercalado por períodos de intensa atividade médica assistencial, foi acomodada. Assim, compatibilizou-se a atividade de mei o período para pesquisa e o outro para atividade médica.

\section{Um paradigma de comportamento profissional}

As atividades nas suas diversas interfaces desde a pura pesquisa básica, passando pel o estudo de pesquisa voltada ao paciente ou ao mecanismo de doença coexistiam. O resultado dessas atividades, ou melhor desta postura científica, induziu a participação do médico-cientista nas principais associações de ciência médica. Nos EUA, foi capitaneada pela American Society for Clinical I nvestigation $(\mathrm{ASCl})$, pela Association of American Physicians (AAP) e pela American Federation of Clinical Research (AFCR). Os grants destinados aos indiví-

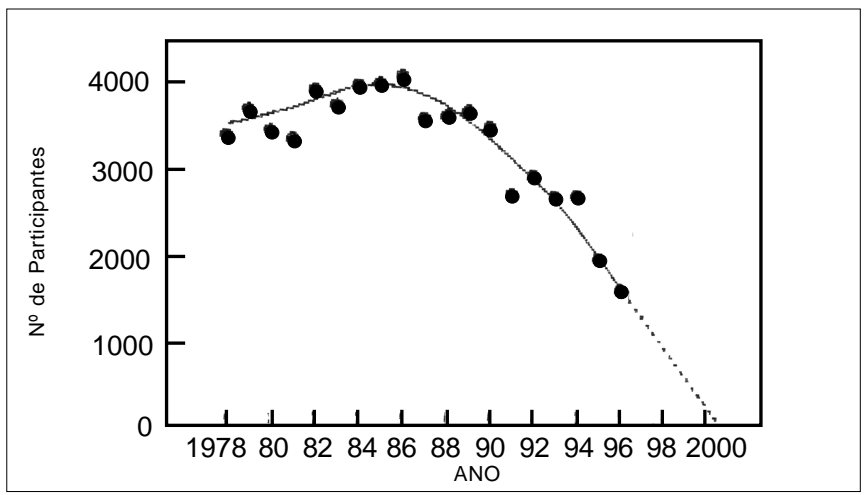

Fig. 2 - Número de parti ci pantes em reuniões anuais da ASCI/ AAP/ AFMR

duos com este perfil que lideravam os principais laboratórios (e departamentos médicos) foi um franco sucesso. As portas estavam abertas para que novos cientistas tivessem condições de obter seus financiamentos aprovados de tal maneira que uma migração interna nos EUA foi significativa, sendo observada a instalação de vários laboratórios, com uma intensa atividade de pesquisa bem como de formação de recursos humanos.

O ponto de virada tem sido observado nesta última década. Talvez um dos marcadores mais interessantes seria o número de médicos-cientistas que participam nos congressos de investi gação clínica, onde a pesquisa básica e a clínica coexistem harmonicamente. A figura 2, modificada de Goldstein e Brown ${ }^{4}$, apresenta o número de partici pantes nos congressos da ASCI/AAP nos últimos 20 anos. N ota-se que a participação entre 1978 a 1990 foi semel hante, variando entre 3.500 e 4.000 congressistas. A partir do início desta década, uma nítida redução ocorreu, sendo que, se projetada para o ano 2000, provavel mente não teremos mais esteti po de encontro científico. Aolado desta observação, para sociedades de especialidade, existe um progressivo aumento no número de participantes, como para a Sociedade de Endocrinologia, de Gastroenterologia, de Cardiologia, de Nefrologia, de Genética Humana, etc. Assim, é nítida a preferência por atividades mais di rigi das, para as especiali idades e mesmo para as subespecialidades.

A interpretação deste dado deve ser cautel osa. Entretanto, pode-se sugerir que o model o médicocientista está sofrendo transformações. O paradigma da ciência médica generalista, onde o médi co poderia desenvolver simultaneamente intensa atividade de pesquisa e intensa atividade médica propriamente dita tem perdido a competitividade nos países do Primeiro Mundo. Esta perda da competitividade, associada à restrição de financiamentos nos EUA pelos $\mathrm{NIH}$, induz mudança de comportamento no jovem investigador. A expectativa de 
se tornar um investigador independente, com a possibilidade em ter seu próprio laboratório financiado, é pouco provável, e apenas uma porcentagem pequena desses investigadores tem tido essa oportunidade. $\mathrm{Na}$ observação de um dos autores (NS) que teve a oportunidade em realizar estágio de pós-doutorado na Harvard Medical School, percebe-se que seus pares no início da década de 80 conseguiram estabel ecer seus serviços em distintas universidades, com seu respectivo laboratório e atividade clínica bem valorizada. Na década de 90, apenas alguns laboratórios independentes foram criados. $O$ destino dos melhores pesquisadores tem sido em se manter associados aos laboratórios estabelecidos, partil hando não só espaço mas também verbas e linhas de pesquisa. Em tese, transportando este fenômeno para o nosso País, este evento parece-nos interessante, pois seria uma forma de absorvermos os novos talentos, a custos reduzidos e, mais ainda, por um período probatório, no sentido de verificarmos a real vocação do pesquisador-médico. Por outro lado, esta associação de certa maneira imposta (sem outra alternativa!) carrega o ranço da cátedra. Existe tendência de se manter uma geronto-hierarquia e não uma ver dadeira hierarquia do saber e do fazer. É claro que existe uma gama variável de situações, sendo al gumas altamente salutares, na dependência da liderança do pesqui sador original no laboratório determinado.

Outra observação interessante diz respeito ao ti po de pesquisador locado nas disci pl inas de medicina. Novamente, no final da década de 70 e no início da de 80, os pesquisadores nos departamentos de medicina eram principalmente médicos. Observação anedótica de um dos autores (NS), sugere que naquele período de $80 \%$ a $90 \%$ dos fellows ou dos pesquisadores associados tinham apenas o título de médico. Nesta década a proporção inverteu-se, e hoje há uma proporção significativa de PhDs ou mesmo MD-PhDs. Esta absorção dos PhDs nos departamentos de medicina nos principais países produtores de ciência é muito bem-vinda, pois desenvolveu-se um sinergismo, sendo que o MD na sua prática médica sofre o desafio frente ao doente e às doenças e traz a pergunta ao laboratório onde trabalha, porém em menor intensidade do que o PhD. A pós esta etapa, ao testar os conhecimentos (ou drogas) geradas no laboratório, o MD passa a ser novamente a estrela da pesquisa voltada para o doente ou para uma determinada doença.

Recentemente na nossa instituição (U nifesp-E scola Paulista de M edicina), propusemo-nos a desenvolver programa de MD/PhD no curso de gradua- ção. A vocação do pesquisador deve preval ecer mas, sem dúvida, o mercado de trabal ho deve influenciar de uma maneira importante o processo decisório profissional. Visando corroborar esta observação, dados recentes do NIH indicam que dos 272 pesquisadores com investimentos aprovados pelo Howard Hughes Medical Institute, uma das principais agências financiadoras privadas dos EUA, 68\% são para $\mathrm{PhDs}$ e $32 \%$ para MDs. Mais ainda, dos $32 \%$ dos MDs, $50 \%$ deles têm associado $\mathrm{PhD}^{5}$.

\section{Oportunidades}

A mudança no perfil do mercado da pesquisa tanto no exterior quanto no Brasil nos últimos anos não si gnifica que o pesquisador-médico esteja condenado à extinção. Ao contrário: como as forças que impulsionam a pesquisa - e até a assistência - em saúde estão atreladas às forças do mercado, a função deste profissional pode ser providencial para muitos empreendimentos. A indústria de bi otecnol ogia americana é um exemplo: no final de 1996 existiam 1.287 empresas de biotecnologia nos EUA, que empregavam $118 \mathrm{mil}$ pessoas. Cerca de $30 \%$ desses profissionais eram PhDs, e quase nenhum era médico-pesquisador (cientista com foco no paciente). As vendas desse setor naquele ano ficaram em torno de US\$ 11 bilhões, e foram gastos US\$ 8 bilhões em pesquisa. O prejuízo ficou em US\$ 4,5 bilhões $^{6}$. Esses números caracterizam um setor que é capaz de identificar um gene novo a cada dia e produzir uma empresa nova a cada semana, mas aprovar apenas uma nova droga por $\mathrm{ano}^{7}$.

De acordo com Goldstein e Brown, o perfil do pesquisador-médico pode ser mais adequado para orientar as pesquisas em função de objetivos centrados nos pacientes e em doenças - objetivos com maior probabilidade de atender as demandas sociais e de mercado.

No Brasil, os escassos investimentos em saúde em si já dificultariam o surgimento dessas oportunidades de trabal ho para esse tipo de pesquisador. Mas pode-se especular que uma aproximação entre a indústria de pesquisa acadêmica e o setor privado possa vir a ocorrer, o que impactaria favoravelmente na oferta de trabal ho para pesquisadores-médicos.

A aproximação já pode estar em curso, tanto no Brasil quanto no exterior (onde já existe um relacionamento estreito entre os setores). Áreas antes consi deradas puramente humanitárias, como projetos assistenciais as regiões carentes do mundo estão recebendo contribuições mais importantes do setor privado: as mais poderosas e influentes organizações de auxílio do mundo, como a Organização Mundial da Saúde e o Banco Mundial, parecem 
convencidos de que uma abordagem socialmente responsável de auxílio à populações carentes pode proporcionar um negócio lucrativo ${ }^{8}$.

Recentemente no Brasil existiam restrições ao relacionamento universidade-indústria. A associação era considerada "pouco nobre" ou mesmo ligada a "uma ciência de segunda categoria". Inclusive argumentos políticos eram levantados, o que dificultou e atrasou esta relação potencial mente frutífera.

Parcerias recentes entre a Universidade F ederal de São Paulo - E scola Paulista de Medicina e o setor privado podem ser o modelo dessa mudança de paradigma no país. Por exemplo, junto com o Laboratório Aché, a universidade deve produzir um fitoterápico derivado da espinheira-santa (Maytenus ilicifolia) para tratar úlceras gástricas. Com o Laboratório Biossintética - e um investimento de $\mathrm{R} \$ 500.000,00$ - está sendo desenvol vida uma droga revigorante derivada da planta conhecida por nóde-cachorro (Heteropteris aphrodisiaca). De uma dessas parcerias deve surgir o primeiro medicamento inteiramente desenvolvido no País ${ }^{9}$ O direcionamento de pesquisas como essas pode, no futuro, criar ou aumentar uma demanda brasileira por médicos-pesquisadores.

\section{SUMMARY}

\section{The physician-scientist: from academy to partnerships}

Objectives. To illustrate the changes in academy and in industry that are reshaping the profile of the physician-scientist.

Methods and results - Data were extracted from theliterature and from primary sources as well as from the authors' own experiences

Conclusions. Within an academy-industry relationship, the market demands a physi cian-scientist best suited to orient research activities towards patient-oriented and disease-oriented goals. [Rev Ass Med Brasil 1999; 45(2): 152-6.]

KEY WORDS: Physician-scientist. Pharmaceutical industry. Basic Research. Clinical Research

\section{REFERÊNCIAS BIBLIOGRÁFICAS}

1 Petti, CH. O Estado deSão Paulo 1998; Maio 16.

2 Scrip 2316. 1998 March 11; 18.

3 Ault, A. US drug makers to boost research funds. Lancet 1998; 351: 274.

4 Goldstein J L, Brown MS. The Clinical Investigator: Bewitched, Bothered, and Bewildered - But Still Beloved. J Clin Invest 1997; 99: 2.803-12.

5 Goldstein J L, Brown MS. The Clinical Investigator: Bewitched, Bothered, and Bewildered - But Still Beloved. J Clin Invest 1997; 99: 2.808.

6 Lee KB J r. , GS Burril. Biotech 97: Alignment - The Eleventh Industry Annual Report. Ernst and Young LLP. Palo Alto; 1996.

7 Goldstein J L, Brown MS. The Clinical Investigator: Bewitched, Bothered, and Bewildered - But Still Beloved. J Clin Invest 99: 1997. 2.810

8 Crowe, S. Public-private partnerships - business as usual. Lancet 1998; 352: 212.

9 Carvalho, MG. O primeiro remédio brasileiro. J ornal da Paulista 1998; 120: 8-9 